\title{
DEHP Down-Regulates Tshr Gene Expression in Rat Thyroid Tissues and FRTL-5 Rat Thyrocytes: A Potential Mechanism of Thyroid Disruption
}

\author{
Min Joo Kim ${ }^{1,2}$, Hwan Hee Kim², Young Shin Song ${ }^{3}$, Ok-Hee Kim ${ }^{4}$, Kyungho Choi ${ }^{5}$, Sujin Kim ${ }^{5,6}$, Byung-Chul Oh, \\ Young Joo Park Pat $^{2,7}$
}

${ }^{1}$ Seoul National University Hospital Healthcare System Gangnam Center; ${ }^{2}$ Department of Internal Medicine, Seoul National University College of Medicine, Seoul; ${ }^{3}$ Department of Internal Medicine, CHA Bundang Medical Center, CHA University, Seongnam; ${ }^{4}$ Department of Physiology, Lee Gil Ya Cancer and Diabetes Institute, Gachon University College of Medicine, Incheon; ${ }^{5}$ Graduate School of Public Health, Seoul National University, Seoul, Korea; ${ }^{6}$ Department of Environmental Science and Institute of Biomedical Studies, Baylor University, Waco, TX, USA; ${ }^{7}$ Department of Molecular Medicine and

Biopharmaceutical Sciences, Graduate School of Convergence Science and Technology, Seoul National University, Seoul, Korea

Background: Di-2-ethylhexyl phthalate (DEHP) is known to disrupt thyroid hormonal status. However, the underlying molecular mechanism of this disruption is unclear. Therefore, we investigated the direct effects of DEHP on the thyroid gland.

Methods: DEHP (vehicle, $50 \mathrm{mg} / \mathrm{kg}$, and $500 \mathrm{mg} / \mathrm{kg}$ ) was administered to Sprague-Dawley rats for 2 weeks. The expression of the thyroid hormone synthesis pathway in rat thyroid tissues was analyzed through RNA sequencing analysis, quantitative reverse transcription-polymerase chain reaction (RT-PCR), and immunohistochemical (IHC) staining. DEHP was treated to FRTL-5 rat thyroid cells, and an RT-PCR analysis was performed. A reporter gene assay containing the promoter of thyroid stimulating hormone receptor (TSHR) in Nthy-ori 3-1 human thyroid cells was constructed, and luciferase activity was determined.

Results: After DEHP treatment, the free thyroxine (T4) and total T4 levels in rats significantly decreased. RNA sequencing analysis of rat thyroid tissues showed little difference between vehicle and DEHP groups. In the RT-PCR analysis, Tshr expression was significantly lower in both DEHP groups (50 and $500 \mathrm{mg} / \mathrm{kg}$ ) compared to that in the vehicle group, and IHC staining showed that TSHR expression in the $50 \mathrm{mg} / \mathrm{kg}$ DEHP group significantly decreased. DEHP treatment to FRTL- 5 cells significantly down-regulated $T s h r$ expression. DEHP treatment also reduced luciferase activity in a reporter gene assay for TSHR.

Conclusion: Although overall genetic changes in the thyroid hormone synthesis pathway are not clear, DEHP exposure could significantly down-regulate $T s h r$ expression in thyroid glands. Down-regulation of $T s h r$ gene appears to be one of potential mechanisms of thyroid disruption by DEHP exposure.

Keywords: Diethylhexyl phthalate; Endocrine disruptors; Thyroid gland; Receptors, thyrotropin

Received: 20 November 2020, Revised: 27 January 2021,

Accepted: 29 January 2021

Corresponding authors: Young Joo Park

Department of Internal Medicine, Seoul National University College of Medicine, 101 Daehak-ro, Jongno-gu, Seoul 03080, Korea

Tel: +82-2-2072-4183, Fax: +82-2-764-2199, E-mail: yjparkmd@snu.ac.kr

Byung-Chul Oh

Department of Physiology, Lee Gil Ya Cancer and Diabetes Institute, Gachon

University College of Medicine, 155 Gaetbeol-ro Yeonsu-gu, Incheon 21999,

Korea

Tel: +82-32-899-6074, Fax: +82-32-899-6246, E-mail: bcoh@gachon.ac.kr

\section{Copyright $(92021$ Korean Endocrine Society}

This is an Open Access article distributed under the terms of the Creative Commons Attribution Non-Commercial License (https://creativecommons.org/ licenses/by-nc/4.0/) which permits unrestricted non-commercial use, distribution, and reproduction in any medium, provided the original work is properly cited. 


\section{INTRODUCTION}

Thyroid disrupting chemicals (TDCs) can interfere with the thyroid hormones [1,2]. The thyroid hormones, thyroxine (T4) and triiodothyronine (T3), are essential for the growth and differentiation of various tissues and organs as well as energy homeostasis and metabolic regulation. Because thyroid hormones are critical in neurocognitive development, maternal thyroid dysfunction during early pregnancy can lead to a lower offspring intelligent quotient (IQ) and neurodevelopmental diseases [3,4]. Therefore, TDCs have important implications for human health [5].

Several chemicals, including phthalates, bisphenols, perchlorate, polychlorinated biphenyls, and polybrominated diphenyl ethers, are known as TDCs [1]. TDCs can affect the hypothalamic-pituitary-thyroid (HPT) axis through various mechanisms [1,6]; these include thyroid hormone synthesis by the thyroid gland, regulation by hypothalamic-pituitary hormones, thyroid hormone-binding proteins, cell uptake of thyroid hormones, thyroid hormone metabolism, and excretion by the liver. Although several chemicals have been identified as TDCs, the mechanisms through which they work remain undetermined. In particular, little is known about the direct effect of TDCs on the thyroid gland. When thyroid stimulating hormone (TSH) binds to a TSH receptor (TSHR) in the thyroid cell membrane, the thyroid hormone synthesis pathway is activated; TSH activates iodine uptake and the transcription of sodium iodide symporter (NIS), thyroglobulin (TG), and thyroperoxidase (TPO). Iodine uptake to thyroid follicular cells is a critical initial step for thyroid hormone synthesis and is mediated by NIS. Iodide is then oxidized by TPO and incorporated into the tyrosyl residues of TG. Iodotyrosines are subsequently coupled with TPO to form $\mathrm{T} 4$ and T3. Therefore, the inhibitions/blockages of this process can reduce thyroid hormone synthesis.

Di-2-ethylhexyl phthalate (DEHP) is one of the most commonly used phthalates. It acts as a plasticizer and softener in various commercial products, including food packaging, building materials, children's toys, medical devices, and cosmetics. Although DEHP is still in use, its impacts on human health are debated [7]. DEHP can affect thyroid hormones and the HPT axis in humans. A recent meta-analysis of previous research showed that urinary concentrations of mono-(2-ethylhexyl) phthalate (MEHP) and mono (2-ethyl-5-hydroxyhexyl) phthalate (MEHHP), which are metabolites of DEHP, were negatively correlated with total T4 [8]. Animal experiments also reported that DEHP exposure reduced total T4 and/or free T4 [9-12].
DEHP exposure to rats changed thyroid histology, including follicular cell hyperplasia and decrease in thyroid follicle size $[9,10,12-14]$. There are some studies on molecular level change within the thyroid gland, but the results of them are conflicting. Liu et al. [12] reported that high dose (500 to $750 \mathrm{mg} / \mathrm{kg}$ ) of DEHP for 30 days down-regulated $T s h r$ expression in thyroid tissues of rats. However, Sun et al. [15] reported that $500 \mathrm{mg} / \mathrm{kg}$ of DEHP increased Tshr mRNA expression and decreased TSHR protein expression in rats. However, long-term exposure to high dose (150 to $600 \mathrm{mg} / \mathrm{kg}$ ) of DEHP for 3 or 6 months increased the expression of TSHR, TG, and TPO in rats [16,17]. Because the results of long-term exposure and in vivo experiments may not be a direct effect of DEHP, we conducted an animal experiment with short-term exposure and in vitro experiment with FRTL-5 rat thyrocytes. In addition, transcriptome analysis in rat thyroid tissues was performed to check the overall genetic changes at once as the effect of DEHP on the liver using RNA sequencing analysis has been previously reported $[18,19]$.

\section{METHODS}

\section{Animals}

Sprague-Dawley male rats were purchased from Orientbio (Seongnam, Korea). The rats were maintained at room temperature with a 12-hour light/12-hour dark cycle. The animals were fed with a chow diet (Picolab Rodent Diet 20, Orientbio) and tap water was available ad libitum. Rats at 8 weeks of age were divided into three groups ( $n=6$ in each group, duplicated): vehicle (corn oil), $50 \mathrm{mg} / \mathrm{kg}$ DEHP (Sigma Aldrich, St. Louis, MO, USA), and $500 \mathrm{mg} / \mathrm{kg}$ DEHP groups ( $n=6$ in each group). The vehicle or DEHP (dissolved in dimethyl sulfoxide [DMSO]) was administered orally by gavage for 2 weeks. All animal experiments were approved by the animal ethics committee of Gachon University, Lee Gil Ya Cancer and Diabetes Institute (LCDI-2016-0079).

\section{Cell cultures}

A fresh subclone of FRTL-5 rat thyroid cells was obtained from the Interthyr Research Foundation (Dr. Leonard D. Kohn, Ohio University, Athens, OH, USA). Cells were grown in a $6 \mathrm{H}$ medium, consisting of Coon's modified F-12 medium supplemented with 5\% calf serum, $1 \mathrm{mM}$ nonessential amino acids, and a mixture of six hormones: bovine TSH (10 U/L), insulin $(10 \mathrm{mg} / \mathrm{L})$, hydrocortisone $(0.4 \mathrm{mg} / \mathrm{L})$, human transferrin $(5 \mathrm{mg} / \mathrm{L})$, glycyll-histidyl-l-lysine acetate $(10 \mu \mathrm{g} / \mathrm{L})$, and somatostatin $(10 \mu \mathrm{g} / \mathrm{L})$. Various concentrations of DEHP (Sigma Aldrich) were admin- 
istered to cells in a $5 \mathrm{H}$ medium, which is the same composition with $6 \mathrm{H}$ except for $\mathrm{TSH}$, with $0.5 \%$ calf serum for 24 hours. DEHP was dissolved in DMSO and then added to culture medium. In the culture media of all groups including the vehicle group, the DMSO concentration was the same as $0.1 \%$.

\section{TSHR luciferase reporter assay}

The human TSHR gene promoter, as defined by the location corresponding to the transcriptional site, was amplified 1,422 bp with polymerase chain reaction (PCR) using the following primers: forward (5'-AAAGGTACC TTCCATAACAATACCATGGT- ${ }^{\prime}$ ) and reverse (5'-AAA CTCGAGTTTCCACGGGACTCGGGGCT-3') and then cloned into the firefly luciferase reporter vector pGL4.14 (Promega, Madison, WI, USA). Nthy-ori 3-1 cells were seeded in 12-well plates at a density of $8 \times 10^{4}$ cells per well in RPMI1640 medium (Welgene, Seoul, Korea) containing $10 \%$ fetal bovine serum 1 day before transfection. After 24 hours, each well was transfected with $200 \mathrm{ng}$ of pGL4.14-hTSHR using $1 \mu \mathrm{L}$ of the transfection reagent Lipofectamine 3000 (Thermo Fisher Scientific, Waltham, MA, USA). Cells were treated with vehicle (dimethyl sufoxide) or 3 to $100 \mathrm{nM}$ concentrations of DEHP. After a 24-hour incubation, the luciferase activity was determined using the Luciferase assay system (Promega) according to the manufacturer instructions. Luminescence was measured with Lumat LB9507 (Berthod Technologies, Bad Wildbad, Germany). To adjust the transfection efficiency, cytomegalovirus (CMV)- $\beta$-gal vector was used and $\beta$-gal activity was quantified by spectrophotometer at $420 \mathrm{nM}$ (VersaMax Microplate Reader, Molecular Devices, Silicon Valley, CA, USA).

\section{Thyroid hormone measurements}

Blood was drawn through an inferior vena cava puncture, and serum was obtained from centrifugation. Serum TSH concentration was measured using an enzyme-linked immunosorbent assay (ELISA) kit (ALPCO, Salem, NH, USA) following the manufacturer's protocol. Total and free T4 were measured by radioimmunoassay kits (Cisbio Bioassays, Codolet, France and Shin Jin Medics Inc., Goyang, Korea, respectively). Total and free T3 were measured by radioimmunoassay kits (Institute of Isotopes Co. Ltd., Budapest, Hungary and Thermo Fisher Scientific, respectively).

RNA isolation from rat thyroid tissues and RNA sequencing Total RNA was extracted from rat thyroid tissues using the TRIzol Reagent (Invitrogen, Carlsbad, CA, USA) according to the manufacturer's instructions. RNA purity was assessed using a NanoDrop spectrophotometer. RNA sequencing was performed per previously established methods [20]; five of the vehicle group and three of each DEHP group. The normalized gene expression values were applied to principal component analysis (PCA) using the 500 most variable genes. The differentially expressed genes (DEGs) were defined by DESeq 2 to have an adjusted $P$ value of $<0.05, \mid \log _{2}$ (fold change) $\mid \geq 1$, and a base mean $\geq 100$, using normalized raw counts of sequencing reads by the regularized log transformation method [21]. To adjust for the multiple testing of 32,494 genes detected by RNA sequencing, the adjusted $P$ value was calculated using the BenjaminiHochberg correction. To construct a heatmap, the centered rlog values were applied to hierarchical clustering using Cluster 3.0 [22]. Pathway enrichment analysis was conducted to determine biologically significant pathways using overlaps of genes of interest with specific gene sets or pathways using the Kyoto Encyclopedia of Genes and Genomes pathway database [23], and detailed methods were described previously [24].

\section{Quantitative reverse transcription-polymerase chain reactions}

After total RNA extraction from rat thyroid tissues or cells, cDNA was synthesized from $1 \mu \mathrm{g}$ of total RNA with the moloney murine leukemia virus (M-MLV) reverse transcriptase kit (Invitrogen). Quantitative reverse transcription-polymerase chain reaction (RT-PCR) was performed using the StepOne Plus real-time PCR system (Applied Biosystems, Foster City, CA, USA) with the SYBR Premix Ex Taq polymerase (Takara Bio Inc., Kusatsu, Japan). The PCR primer sets are listed in Supplemental Table S1.

\section{Immunohistochemical staining analysis}

Paraffin-embedded thyroid tissues were sectioned to a thickness of $4 \mu \mathrm{m}$. The sections were incubated with primary antibodies for TSHR (goat polyclonal antibody [sc-7816]; Santa Cruz Biotechnology, Santa Cruz, CA, USA) and NIS (rabbit polyclonal antibody [bs-0448R]; Bioss, Beijing, China) overnight at $4^{\circ} \mathrm{C}$. After washing, the sections were incubated with secondary antigoat or anti-rabbit antibody for 1 hour at room temperature and then treated with the Elite $\mathrm{ABC}$ kit reagent (Vector Laboratories Ltd., Burlingame, CA, USA) for 30 minutes. For color development, the tissue sections were stained with the 3,3'-diaminobenzidine peroxidase substrate solution (Vector Laboratories Ltd.) and counterstained with Mayer's hematoxylin (Sigma-Aldrich). The sections were examined under a light microscope after 
mounting with Permount Mounting Medium (Thermo Fisher Scientific). Immunoreactivity was evaluated semi-quantitatively using Image J software (National Institutes of Health, Bethesda, MD, USA).

\section{Statistical analysis}

Data in the figure was presented as a box-and-whisker plot. Serum thyroid hormones and mRNA expression among groups (vehicle and DEHP groups) were compared using one-way analysis of variance (ANOVA) or Kruskal-Wallis test. The statistical analysis was performed using GraphPad Prism version 7.0 software (GraphPad Software Inc., San Diego, CA, USA). $P<0.05$ was considered to be significant.

\section{RESULTS}

\section{Serum thyroid hormones in rats}

During DEHP treatment for 2 weeks, there were no overt signs of systemic toxicity in rats. Body weights, liver function, and renal function in DEHP groups were not significantly different from those of the vehicle group (Supplemental Table S2). DEHP treatment significantly reduced free T4 and total T4 (Fig. 1), suggesting thyroid-disruption.

\section{mRNA expressions in rat thyroid tissues}

To determine whether the hormonal changes are associated with pathological changes in the thyroid glands, RNA sequencing analysis was performed using thyroid tissues of rats. The PCA analysis showed no different clustering between DEHP and vehicle groups (Fig. 2A). Subsequently, the up-regulated or downregulated genes in the DEHP groups (50 and $500 \mathrm{mg} / \mathrm{kg}$ ) compared to the vehicle group were identified (Supplemental Fig.
$\mathrm{S} 1$ ), and the top 10 DEGs were presented in Table 1. However, those genes were not related to thyroid hormone synthesis. The pathway related to thyroid hormone synthesis was not changed, although the pathway enrichment analysis showed changes in some gene sets related to circadian rhythm, oocyte meiosis, and cell cycle (Supplemental Table S3). Next, the expression of individual genes related to thyroid hormone synthesis and thyroid differentiation was analyzed (Fig. 2B). The expressions of Sl$c 5 a 5$ and Tpo in the $500 \mathrm{mg} / \mathrm{kg}$ DEHP group were significantly higher than those in the vehicle group (Fig. 2C). The expression of the other genes including $T s h r$ was not significantly different between groups.

\section{TSHR expression in rat thyroid tissues}

To confirm these results, quantitative RT-PCR analysis with rat thyroid tissues was performed. DEHP treatment significantly decreased $T_{s} h r$ mRNA expression in both 50 and $500 \mathrm{mg} / \mathrm{kg}$ DEHP groups and increased Slc5a5 mRNA expression in the $500 \mathrm{mg} / \mathrm{kg}$ DEHP group (Fig. 3A). Protein expressions of TSHR and NIS were evaluated using immunohistochemical staining. TSHR expression in the $50 \mathrm{mg} / \mathrm{kg}$ DEHP group was significantly decreased compared to that in the vehicle group (Fig. 3B). However, NIS (Slc5a5) expression was not different between the DEHP and vehicle groups (Fig. 3C). This suggests that DEHP suppresses TSHR expression but not NIS expression in thyroid glands.

\section{TSHR expression in thyroid cells}

To clarify whether DEHP affects thyroid tissues directly, in vitro experiments using FRTL-5 rat normal thyrocytes were performed. DEHP treatment above $10 \mu \mathrm{M}$ significantly down-regulated $T s h r$ expression in a dose-dependent manner (Fig. 4A).
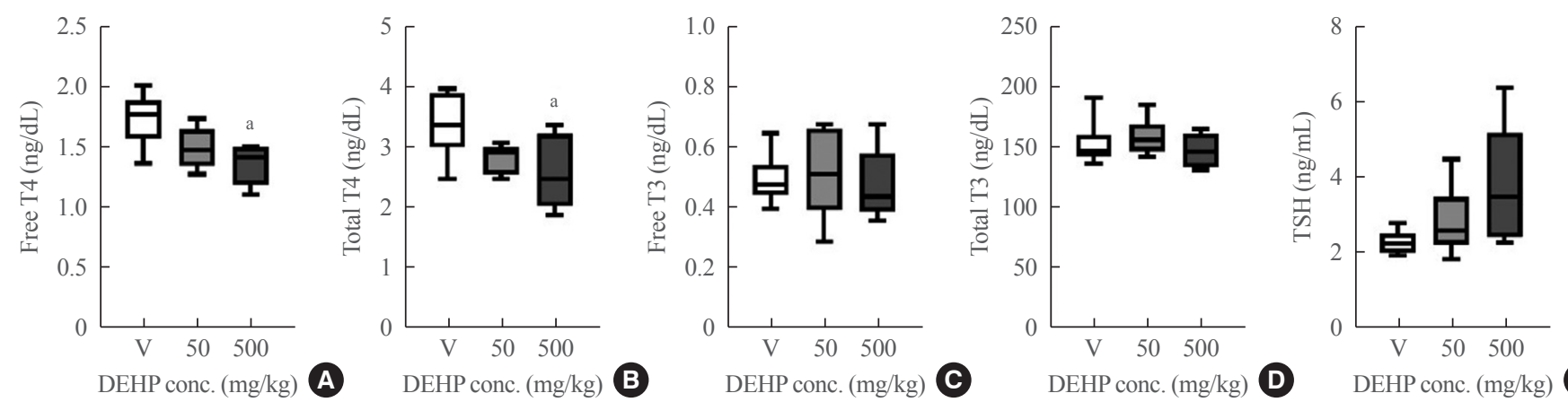

Fig. 1. Serum thyroid hormones in di-2-ethylhexyl phthalate (DEHP)-treated rats. After DEHP treatments (vehicle, $50 \mathrm{mg} / \mathrm{kg}$, or $500 \mathrm{mg} / \mathrm{kg}$ DEHP) for 2 weeks, thyroid function test was performed with obtained rat blood ( $n=6$ to 12). (A) Free thyroxine (T4), (B) total T4, (C) free triiodothyronine (T3), (D) total T3, (E) thyroid stimulating hormone (TSH). One-way analysis of variance (ANOVA) with Tukey's multiple comparisons test was performed. conc, concentration. ${ }^{a} P<0.05$ compared to the vehicle group. 

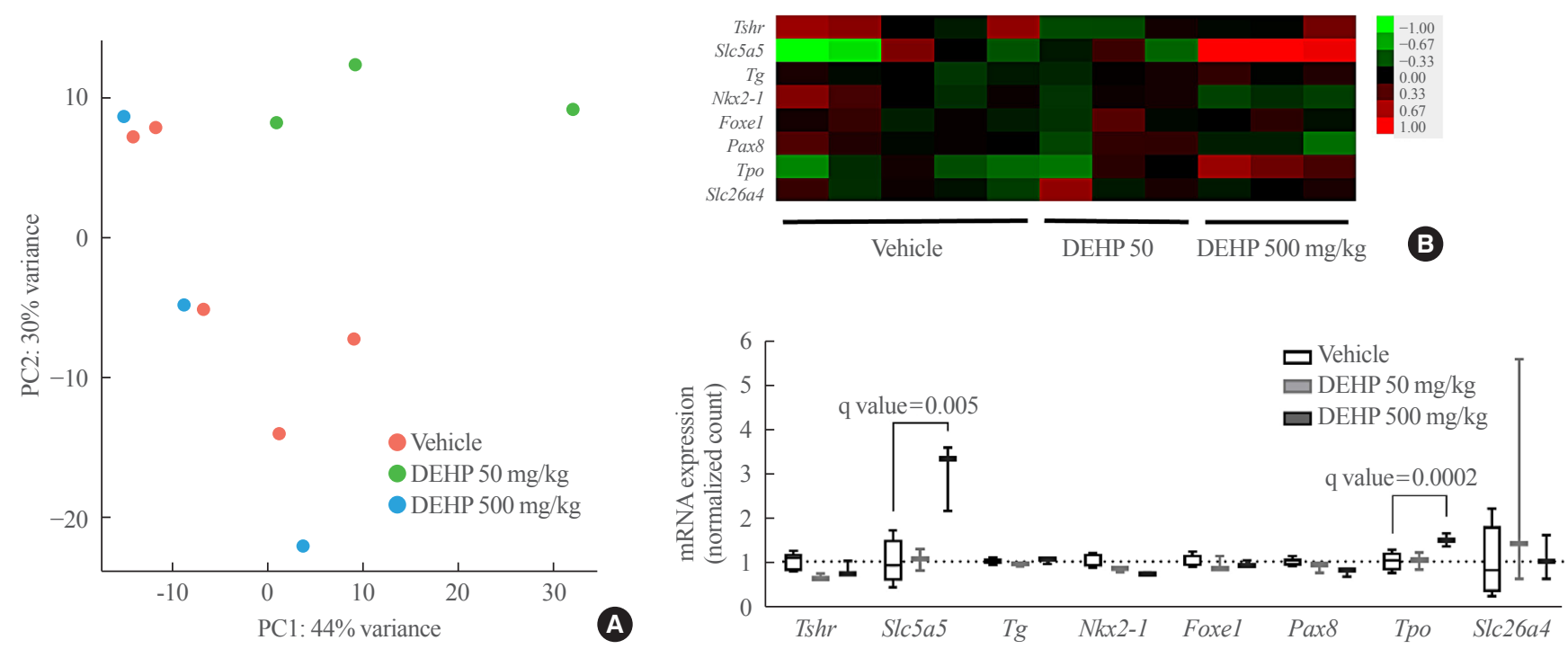

Fig. 2. mRNA sequencing data of rat thyroid tissues treated with di-2-ethylhexyl phthalate (DEHP) for 2 weeks. (A) Principal component analysis. (B) Heatmap of genes related to thyroid hormone synthesis and thyroid differentiation. (C) Box plots of genes related to thyroid hormone synthesis and thyroid differentiation. PC, principal component.

Table 1. Top 10 Differentially Expressed Genes in Thyroid Tissues of Rats

\begin{tabular}{|c|c|c|c|c|c|c|c|}
\hline \multicolumn{4}{|c|}{ Down-regulated genes } & \multicolumn{4}{|c|}{ Up-regulated genes } \\
\hline Gene & Base mean & $\begin{array}{c}\log _{2} \\
\text { fold change }\end{array}$ & $\begin{array}{c}\text { Adjusted } \\
P \text { value }\end{array}$ & Gene & Base mean & $\begin{array}{l}\log _{2} \\
\text { fold change }\end{array}$ & $\begin{array}{c}\text { Adjusted } \\
P \text { value }\end{array}$ \\
\hline Armcx6 & 238 & -0.547 & $1.29 \times 10^{-7}$ & Hsph1 & 1,720 & 0.769 & $1.87 \times 10^{-5}$ \\
\hline Esyt3 & 481 & -0.655 & $2.69 \times 10^{-6}$ & $D b p$ & 2,160 & 0.894 & $1.87 \times 10^{-5}$ \\
\hline Adamts4 & 255 & -0.707 & $1.16 \times 10^{-4}$ & Per3 & 899 & 0.712 & $1.16 \times 10^{-4}$ \\
\hline Arntl & 612 & -0.731 & $4.14 \times 10^{-4}$ & Nrldl & 1,988 & 0.820 & $3.14 \times 10^{-4}$ \\
\hline Npas2 & 1,902 & -0.674 & 0.002 & $\operatorname{Nr} 1 d 2$ & 1,493 & 0.598 & $3.48 \times 10^{-4}$ \\
\hline Tulp1 & 144 & -0.557 & 0.004 & Tef & 1,555 & 0.701 & $3.80 \times 10^{-4}$ \\
\hline Ankrd29.1 & 516 & -0.562 & 0.005 & Pex5l & 202 & 0.720 & $3.97 \times 10^{-4}$ \\
\hline Сур26b1 & 241 & -0.663 & 0.007 & Gtse1 & 112 & 0.735 & 0.002 \\
\hline Lonrf3 & 123 & -0.608 & 0.012 & $R c c 2$ & 955 & 0.509 & 0.004 \\
\hline Arhgap20 & 122 & -0.568 & 0.015 & Per2 & 659 & 0.634 & 0.004 \\
\hline
\end{tabular}

Genes in di-2-ethylhexyl phthalate (DEHP) group $(50$ and $500 \mathrm{mg} / \mathrm{kg}$ ) were compared with those in the vehicle group.

The Slc5a5 expression did not show any significant change. Furthermore, the effects of DEHP on the TSHR gene were determined using a reporter gene assay in Nthy-ori 3-1 cells. Compared to the vehicle group, DEHP treatment above $10 \mu \mathrm{M}$ significantly reduced the luciferase activity by $20 \%$ (Fig. 4B).

\section{DISCUSSION}

DEHP is a well-known TDC, and it can affect thyroid hormone synthesis. This study demonstrates that DEHP has the potential to decrease thyroid hormone synthesis by inhibiting Tshr transcription. DEHP treatment significantly down-regulated the expression of $T s h r$ gene both in rat and human thyroid cells. DEHP treatment to rats also reduced TSHR expression.

Epidemiological studies can demonstrate that TDC exposure is associated with decreasing thyroid hormone levels; however, the mechanism through which TDC disrupts thyroid hormones is challenging to examine in humans. Therefore, the mechanism 

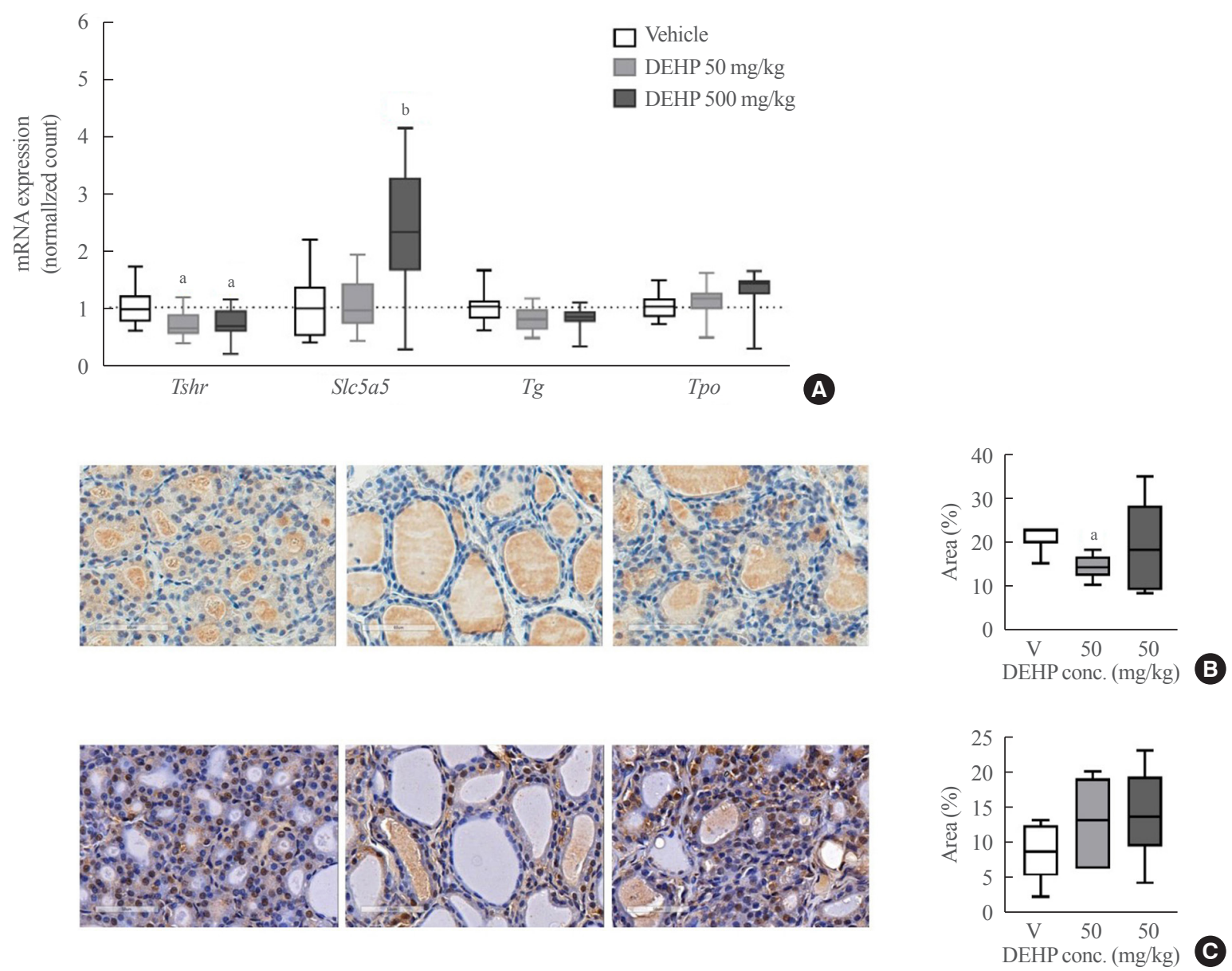

Fig. 3. Expression of gene related to thyroid hormone synthesis in rat thyroid tissues ( $n=6$ to 12$)$ treated with di-2-ethylhexyl phthalate (DEHP) for 2 weeks. (A) Reverse transcription-polymerase chain reaction (RT-PCR) analysis. (B) Representative image of thyroid stimulating hormone receptor (TSHR) immunohistochemical (IHC) staining (1:100) and quantification of TSHR positive area per total area (\%). (C) Representative image of sodium iodide symporter (NIS) IHC staining (1:100) and quantification of TSHR positive area per total area (\%). One-way analysis of variance (ANOVA) with Tukey's multiple comparisons test was performed. conc, concentration. ${ }^{\mathrm{a}} P<0.05$; ${ }^{\mathrm{b}} P<0.01$.
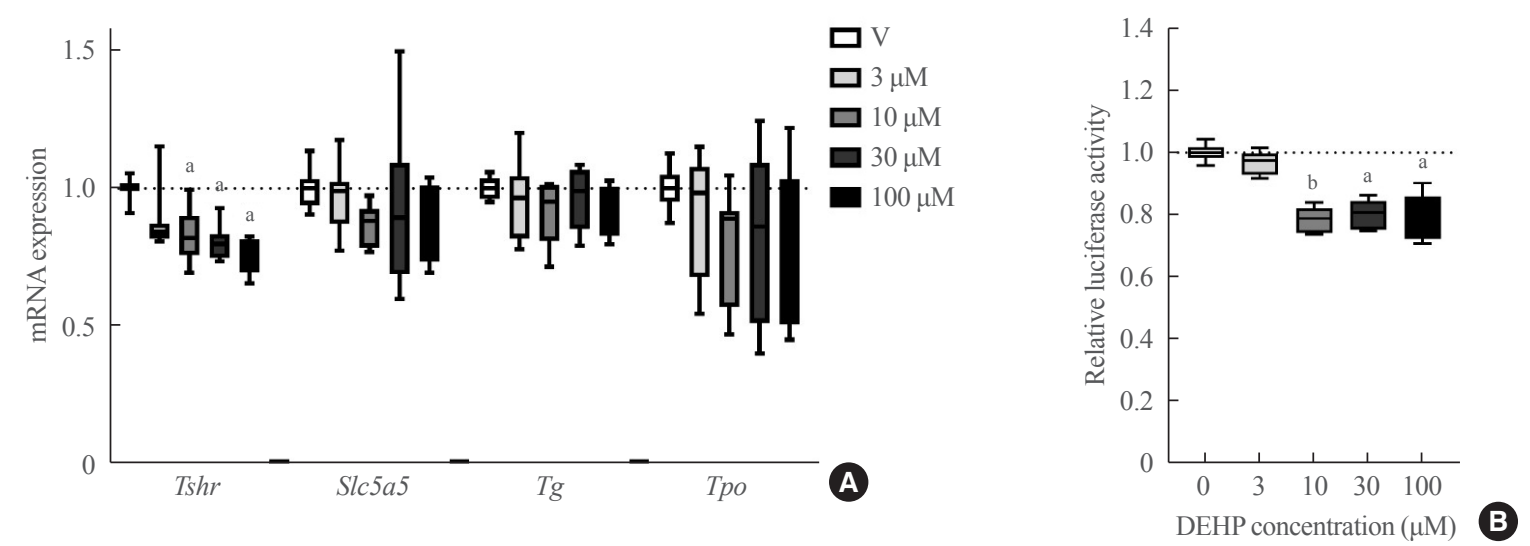

Fig. 4. Expression of gene related to thyroid hormone synthesis in thyroid cells treated with di-2-ethylhexyl phthalate (DEHP). (A) mRNA expression level of genes related to thyroid hormone synthesis ( $T s h r, S l c 5 a 5, T g$, and Tpo) in FRTL-5 cells treated with DEHP for 24 hours. (B) Thyroid stimulating hormone receptor (TSHR) luciferase reporter assay. Luciferase activity in Nthy-ori 3-1 cells treated with DEHP for 24 hours. ${ }^{\mathrm{a}} \mathrm{P}<0.05 ;{ }^{\mathrm{b}} \mathrm{P}<0.01$. 
has been studied through animal or cell experiments. In rat experiments, DHEP treatment significantly reduced total T4 and/ or free T4 [9-11]. DEHP exposure also induced histological changes of the thyroid glands in rats $[9,10,12,13]$, suggesting a direct effect of DEHP on thyroid hormone synthesis. However, the detailed molecular mechanism of this effect was unclear. In this study, genetic changes were extensively investigated using RNA sequencing; however, the overall change in the thyroid hormone synthesis pathway was not significant. Only decreased $T s h r$ expression in DEHP groups were consistently observed in rat thyroid tissues. In vitro cell experiments, including a reporter gene assay, also demonstrated that DEHP could directly downregulate $T s h r$ expression in thyrocytes. As TSH is the most important stimulant for thyroid hormone synthesis, a decrease in TSHR can weaken the TSH signal, leading to a reduction in serum thyroid hormone. This study observed that a $500 \mathrm{mg} / \mathrm{kg}$ DEHP treatment increased mRNA expression of NIS (Slc5a5) in rat thyroid tissues. However, the changes in the protein expression of NIS in rat thyroid tissues were not significant. It has been reported that the treatment of MEHP, a metabolite of DEHP, increased mRNA expression of NIS in zebrafish [25], whereas DEHP treatment did not change protein expressions of NIS in rat thyroid tissues [9]. DEHP treatment to FRTL-5 cells did not increase the mRNA expression of NIS in this study. Therefore, the changes in NIS within thyroid tissues or thyrocytes seem to be secondary or compensatory responses.

Although this study suggested that DEHP has the potential to directly affect the thyroid gland and reduce thyroid hormone synthesis, the impact may be small. RNA sequencing analysis of rat thyroid tissues showed that the overall change in the thyroid hormone synthesis pathway was not significant. Because RNA sequencing analysis was conducted with a small number of samples ( $n=3$ to 5 ), there is a possibility of false negatives. RT-PCR analysis with more number of samples showed that DEHP treatment to rat or thyroid cells down-regulated $T s h r$ expression, but the expression of other genes related to thyroid hormone synthesis did not change. This suggests that DEHP disrupts the thyroid hormone system through pathways other than those within the thyroid gland; there are various possible mechanisms that have been reported $[1,2]$. DEHP exposure to rats altered expressions of thyrotopin-releasing hormone receptor (TRHR) and TSH $\beta$ in rat hypothalamus/pituitary tissues $[9,10,12,15,16]$. This suggests that DEHP can affect thyroid hormone regulation through the hypothalamic-pituitary hormone. DEHP exposure to rats or zebrafish decreased transthyretin, a major binding protein that transports thyroid hormones in blood $[9,12]$. DEHP exposure to rats or zebrafish altered deiodinase 1 activity and induced UDP-glucuronosyltrasferase 1A1 (UGT1A1) and sulfotransferase 1E1 (SULT1E1) in the liver $[9,10,12,15,25]$, hepatic enzymes related to thyroid hormone metabolism. It suggested that DEHP can affect thyroid hormone metabolism, resulting in thyroid hormone changes.

In conclusion, DEHP exposure could down-regulate $T s h r$ gene directly in thyroid glands of rats, leading to a decreased thyroid hormone synthesis. Other direct and indirect mechanisms of thyroid hormone disruption in addition to $T s h r$ gene down-regulation deserve further investigation.

\section{CONFLICTS OF INTEREST}

No potential conflict of interest relevant to this article was reported.

\section{ACKNOWLEDGMENTS}

This study was funded by a grant (18182MFDS365) from Ministry of Food and Drug Safety in 2018.

\section{AUTHOR CONTRIBUTIONS}

Conception or design: M.J.K., K.C., S.K., B.C.O., Y.J.P. Acquisition, analysis, or interpretation of data: M.J.K., H.H.K., Y.S.S., O.H.K., B.C.O. Drafting the work or revising: M.J.K., Y.S.S., O.H.K., S.K., B.C.O., Y.J.P. Final approval of the manuscript: M.J.K., H.H.K., Y.S.S., O.H.K., K.C., S.K., B.C.O., Y.J.P.

\section{ORCID}

Min Joo Kim https://orcid.org/0000-0002-9765-9340

Byung-Chul Oh https://orcid.org/0000-0002-4277-7083

Young Joo Park https://orcid.org/0000-0002-3671-6364

\section{REFERENCES}

1. Gore AC, Chappell VA, Fenton SE, Flaws JA, Nadal A, Prins GS, et al. EDC-2: the Endocrine Society's second scientific statement on endocrine-disrupting chemicals. Endocr Rev 2015;36:E1-150.

2. Boas M, Feldt-Rasmussen U, Main KM. Thyroid effects of endocrine disrupting chemicals. Mol Cell Endocrinol 2012; 355:240-8.

3. Haddow JE, Palomaki GE, Allan WC, Williams JR, Knight 
GJ, Gagnon J, et al. Maternal thyroid deficiency during pregnancy and subsequent neuropsychological development of the child. N Engl J Med 1999;341:549-55.

4. Henrichs J, Bongers-Schokking JJ, Schenk JJ, Ghassabian A, Schmidt HG, Visser TJ, et al. Maternal thyroid function during early pregnancy and cognitive functioning in early childhood: the generation R study. J Clin Endocrinol Metab 2010; 95:4227-34.

5. Mughal BB, Fini JB, Demeneix BA. Thyroid-disrupting chemicals and brain development: an update. Endocr Connect 2018;7:R160-86.

6. Jugan ML, Levi Y, Blondeau JP. Endocrine disruptors and thyroid hormone physiology. Biochem Pharmacol 2010;79: 939-47.

7. Miles-Richardson SR, Bosch S, Swarts S, Llados F, Gray DA. Toxicological profile for di(2-Ethylheyl)phthalate (DEHP). Atlanta: Department of Health and Human Services; 2002.

8. Kim MJ, Moon S, Oh BC, Jung D, Choi K, Park YJ. Association between diethylhexyl phthalate exposure and thyroid function: a meta-analysis. Thyroid 2019;29:183-92.

9. Zhang P, Guan X, Yang M, Zeng L, Liu C. Roles and potential mechanisms of selenium in countering thyrotoxicity of DEHP. Sci Total Environ 2018;619-620:732-9.

10. Ye H, Ha M, Yang M, Yue P, Xie Z, Liu C. Di2-ethylhexyl phthalate disrupts thyroid hormone homeostasis through activating the Ras/Akt/TRHr pathway and inducing hepatic enzymes. Sci Rep 2017;7:40153.

11. Yamaguchi T, Maeda M, Ogata K, Abe J, Utsumi T, Kimura $\mathrm{K}$. The effects on the endocrine system under hepatotoxicity induction by phenobarbital and di(2-ethylhexyl)phthalate in intact juvenile male rats. J Toxicol Sci 2019;44:459-69.

12. Liu C, Zhao L, Wei L, Li L. DEHP reduces thyroid hormones via interacting with hormone synthesis-related proteins, deiodinases, transthyretin, receptors, and hepatic enzymes in rats. Environ Sci Pollut Res Int 2015;22:12711-9.

13. Howarth JA, Price SC, Dobrota M, Kentish PA, Hinton RH. Effects on male rats of di-(2-ethylhexyl) phthalate and di-nhexylphthalate administered alone or in combination. Toxicol Lett 2001;121:35-43.

14. Kim M, Jeong JS, Kim H, Hwang S, Park IH, Lee BC, et al. Low dose exposure to di-2-ethylhexylphthalate in juvenile rats alters the expression of genes related with thyroid hormone regulation. Biomol Ther (Seoul) 2018;26:512-9.

15. Sun D, Zhou L, Wang S, Liu T, Zhu J, Jia Y, et al. Effect of di-(2-ethylhexyl) phthalate on the hypothalamus-pituitarythyroid axis in adolescent rat. Endocr J 2018;65:261-8.

16. Dong X, Dong J, Zhao Y, Guo J, Wang Z, Liu M, et al. Effects of long-term in vivo exposure to di-2-ethylhexylphthalate on thyroid hormones and the TSH/TSHR signaling pathways in Wistar rats. Int J Environ Res Public Health 2017;14:44.

17. Kim S, Park GY, Yoo YJ, Jeong JS, Nam KT, Jee SH, et al. Di-2-ethylhexylphthalate promotes thyroid cell proliferation and DNA damage through activating thyrotropin-receptormediated pathways in vitro and in vivo. Food Chem Toxicol 2019;124:265-72.

18. Zhang L, Hu Y, Sun W, Chen S, Jia X, Cai W. Transcriptomic responses of Nile tilapia (Oreochromis niloticus) liver to environmental concentration of di(2-ethylhexyl)phthalate. Ecotoxicol Environ Saf 2018;165:70-7.

19. Huff M, da Silveira WA, Carnevali O, Renaud L, Hardiman G. Systems analysis of the liver transcriptome in adult male zebrafish exposed to the plasticizer (2-ethylhexyl) phthalate (DEHP). Sci Rep 2018;8:2118.

20. Yoo SK, Lee S, Kim SJ, Jee HG, Kim BA, Cho H, et al. Comprehensive analysis of the transcriptional and mutational landscape of follicular and papillary thyroid cancers. PLoS Genet 2016;12:e1006239.

21. Love MI, Huber W, Anders S. Moderated estimation of fold change and dispersion for RNA-seq data with DESeq2. Genome Biol 2014;15:550.

22. de Hoon MJ, Imoto S, Nolan J, Miyano S. Open source clustering software. Bioinformatics 2004;20:1453-4.

23. Ogata H, Goto S, Sato K, Fujibuchi W, Bono H, Kanehisa M. KEGG: Kyoto Encyclopedia of Genes and Genomes. Nucleic Acids Res 1999;27:29-34.

24. Cho BA, Yoo SK, Song YS, Kim SJ, Lee KE, Shong M, et al. Transcriptome network analysis reveals aging-related mitochondrial and proteasomal dysfunction and immune activation in human thyroid. Thyroid 2018;28:656-66.

25. Zhai W, Huang Z, Chen L, Feng C, Li B, Li T. Thyroid endocrine disruption in zebrafish larvae after exposure to mono-(2ethylhexyl) phthalate (MEHP). PLoS One 2014;9:e92465. 